\title{
Design of Elevons, Wings, and Performance Investigation for A Blended Wing Body UAV
}

\author{
Ashutosh Kumar, Raghvendra Gautam
}

\begin{abstract}
Objectives: To study a hybrid VTOL- Blended wing body design for its wings and elevons and perform CFD simulations with the wings. The steps for designing wing configuration and Elevon positioning involve different variables giving rise to a large number of design possibilities for a control surface. In the current study methods, have been proposed for the selection of optimized wing configuration and elevons positioning and validated with simulations model. Methods: Meta-heuristic methods like genetic algorithms are used for arriving at favorable solutions and Matlab coding is written for the initial draft of wing geometry, selected geometries are iterated in XFLR5 for stability and control, and later validated with simulations around the fluid domain. Elevons are control surfaces generally installed in tailless aircraft at the wing's trailing edge. It applies to roll and pitching force to wings as it combines the functionality of both pitching and rolling control. Design space was mathematically plotted and solved using MATLAB to decide elevons, wing configuration, and their positions.Findings: Initial selection of wing geometry, aoa, and structural design for maneuverability and stability for the enhanced aerodynamic performance of $B W B$ $U A V$. In this presented paper drag coefficient of the designed $B W B$ UAV comes out to be precisely around 0.02216 using computational modeling. Variation curve of Lift and drag coefficient with aspect ratio and angle of attack. Post-processing results of pressure forces and velocity profile on Wings accurately validate the proposed method of control surface optimization. Novelty: Designed BWB UAV has increased lift to drag ratio, reduced weight of airframe which improves performance. The Design phase is highly iterative, Through this research paper, an attempt has been made to develop a methodology for selection and investigation of control surfaces against requirements that makes BWB UAV more helpful for practical use and increasing the lift and endurance efficiency of the hybrid VTOL- Blended wing body aircraft.
\end{abstract}

Keywords: UAV, Elevon, Wing, Matlab, XFLR5, CFD

\section{INTRODUCTION}

$\mathrm{T}_{\text {he }}$ BWB UAV can be used for surveillance and reconnaissance and being a VTOL-aircraft, it is lightweight which makes it portable and easy to launch but designing is a real challenge due to the limited stability of control surfaces. A UAV has two classes of surfaces: one is lifting surfaces, the other is control surfaces.

Manuscript received on September 08, 2021.

Revised Manuscript received on September 15, 2021.

Manuscript published on October 30, 2021.

* Correspondence Author

Ashutosh Kumar*, Research Scholar, Department of Mechanical Engineering, Delhi Technological University, Shahbad Daulatpur, Main Bawana Road, Delhi, India

Raghvendra Gautam, Assistant Professor, Department of Mechanical Engineering, Delhi Technological University, Shahbad Daulatpur, Main Bawana Road, Delhi, India

(c) The Authors. Published by Blue Eyes Intelligence Engineering and Sciences Publication (BEIESP). This is an open access article under the CC BY-NC-ND license (http://creativecommons.org/licenses/by-nc-nd/4.0/)
In an aircraft, the lifting surfaces which have tails and wings attached are used to generate aerodynamic lift force while the aircraft is controlled through devices called control surfaces. Most conventional UAVs make use of the elevator, aileron, and rudder as primary flight control surfaces. But due to increasing complexity in design and requirements use of unconventional flight control surfaces is also becoming prominent. Unconventional flight control surfaces include surfaces such as elevons, flaperons, asymmetric spoilers, ruddervators, split rudders, and drag-rudders, etc[1]. The main objective behind this research work is to develop a methodology to be used by airframe engineers to investigate the effectiveness of their control surface against their requirements. The control surface design process is highly iterative and hence a systematic approach needs to be followed. Before conducting this research, an extensive study was done on fluid dynamics \& aerodynamics which luded the design of wings from the works of Daniel $\mathrm{P}$. ner [1], John D. Anderson [2]. The design process entrol surface configuration based A code, and then meshing and simulations are . Raymer, D.P discusses the introduction to control systems [1]. Sadraey.M, Colgan. R in research paper a unconventional control surfaces for UAVs deals with the conceptual design involved in the design methodology [3]. Sadraey.M in research paper Aircraft Design: A system engineering Approach addresses the classification of aircraft based on the aircraft characteristics. It also provides data for classifying different flight phases into different categories and rolls control requirements are also studied as per the inary standards [4]. Sadraey. M, Colgan. R, in a research a systems engineering approach to the design of control surfaces for UAVs discusses various steps involved in elevon designing [5]. Mathworks document deals with the use of MATLAB $\subset$ software for writing the code [6]. The design process of such UAVs which are used in HADR missions( Humanitarian Aid and Disaster Relief ) is not well understood since enough literature is not available and with complex systems and variables present, design and its optimization of a UAV is a serious challenge. Hence this paper on control surfaces optimization and the effect of winglets on the performance of UAVs is our attempt to provide future researchers and engineers in designing.

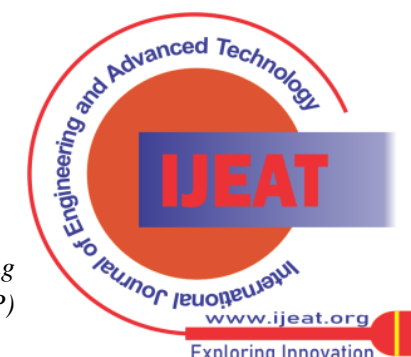




\section{Design of Elevons, Wings, and Performance Investigation for A Blended Wing Body UAV}

While solving the problem through this method an assumption is taken that the flow is incompressible and the boundary layer is resolved independently, turbulence model k-omega SST is used and meshing is done on Hex dominant algorithm and after which post-processing simulations are done Though the package gives a fair estimate of aerodynamic coefficients the values are still inaccurate. Therefore, to get accurate results all the aerodynamic analysis is done using computational fluid dynamics methodology

\section{CONCEPTUAL DESIGN}

\subsection{Wing Design}

A. Statement of Objective - The critical design requirements formulated for the design of UAVs are called the Statement of Objectives, based on which mathematical models and calculations are made and the conceptual design is initiated.

Table 1A. Initial Parameters

\begin{tabular}{|l|l|}
\hline Parameter & Objectives \\
\hline $\begin{array}{l}\text { GTOW (gross take-off } \\
\text { weight) }\end{array}$ & $7 \mathrm{~kg}$ \\
\hline Payload Weight & $<2 \mathrm{~kg}$ \\
\hline $\begin{array}{l}\text { Endurance( Battery } \\
\text { Cap/ current ) }\end{array}$ & $2 \mathrm{hrs}$ \\
\hline Cruise speed & $32 \mathrm{~m} / \mathrm{s}$ \\
\hline
\end{tabular}

1. Variables

Wing span, b

Aspect ratio, AR

Taper ratio, $\lambda$

Leading edge sweep, A

Tip twist, $\theta$
Table 1 B. Constraint Parameters

\begin{tabular}{|l|l|}
\hline Parameter & \multicolumn{1}{|l|}{ Range } \\
\hline Taper Ratio & $0.3-0.6$ \\
\hline Aspect Ratio & 05-Sep \\
\hline Taper Twist & -2 to -7 degrees \\
\hline Leading Edge Sweep & $20-27$ degrees \\
\hline Span & $0.6-0.7 \mathrm{~m}$ \\
\hline
\end{tabular}

\section{B. Initial Sizing}

The sizing problem of wing design primarily includes 5 variables namely Taper ratio, Sweep, span, Aspect ratio, and Tip twist. The nature of these design variables and the intertwined aerodynamic relations involving them gives rise to a large number of design possibilities and is a multiobjective optimization problem. Meta-heuristic methods like genetic algorithms prove to be a useful tool in dodging local optima and converging on a favorable solution with multiple constraints and conflicting objectives. As a result, a MATLAB code was written to arrive at an initial draft of the wing geometry. The input constraints, variables, and objectives [7] are shown in Figure 1.

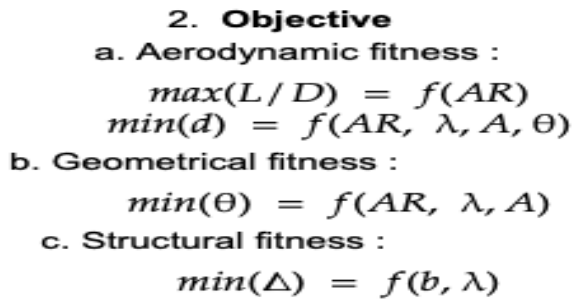

where $d=$ Difference of area between actual and elliptical lift distribution curves $\Delta=$ Deflection at tip

Figure 1 Input constraint variables

The algorithm works by initiating a random population of different wing geometries with the process parameters listed in Table $1 \mathrm{~A}$ and $1 \mathrm{~B}$. The random population converges to an optimum solution given enough time as the net fitness of the generation reaches a maximum saturation point. The results of the Meta-heuristic methods like genetic algorithms are presented in Figures 2 and 3. The curve (Figure 3) gives a graphical representation of the increase in average fitness of each generation and clearly shows that the geometry converges to the most optimal solution as the fitness reaches a saturation value. The short-listed geometries were then iterated rigorously on XFLR5 software to accommodate objectives like stability and control. The calculations conducted at this stage do take into account the lifting nature of the fuselage. This is done at a later design stage using the CFD. Designing for an optimal control surface having a better center of gravity and static stability, a curve with green color on (Figure 2) wing geometry vs wing span characteristic curve is an excellent choice for improved aerodynamic efficiency.

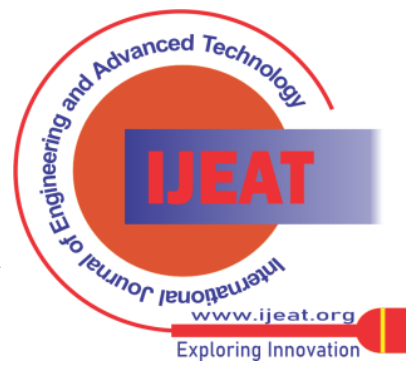




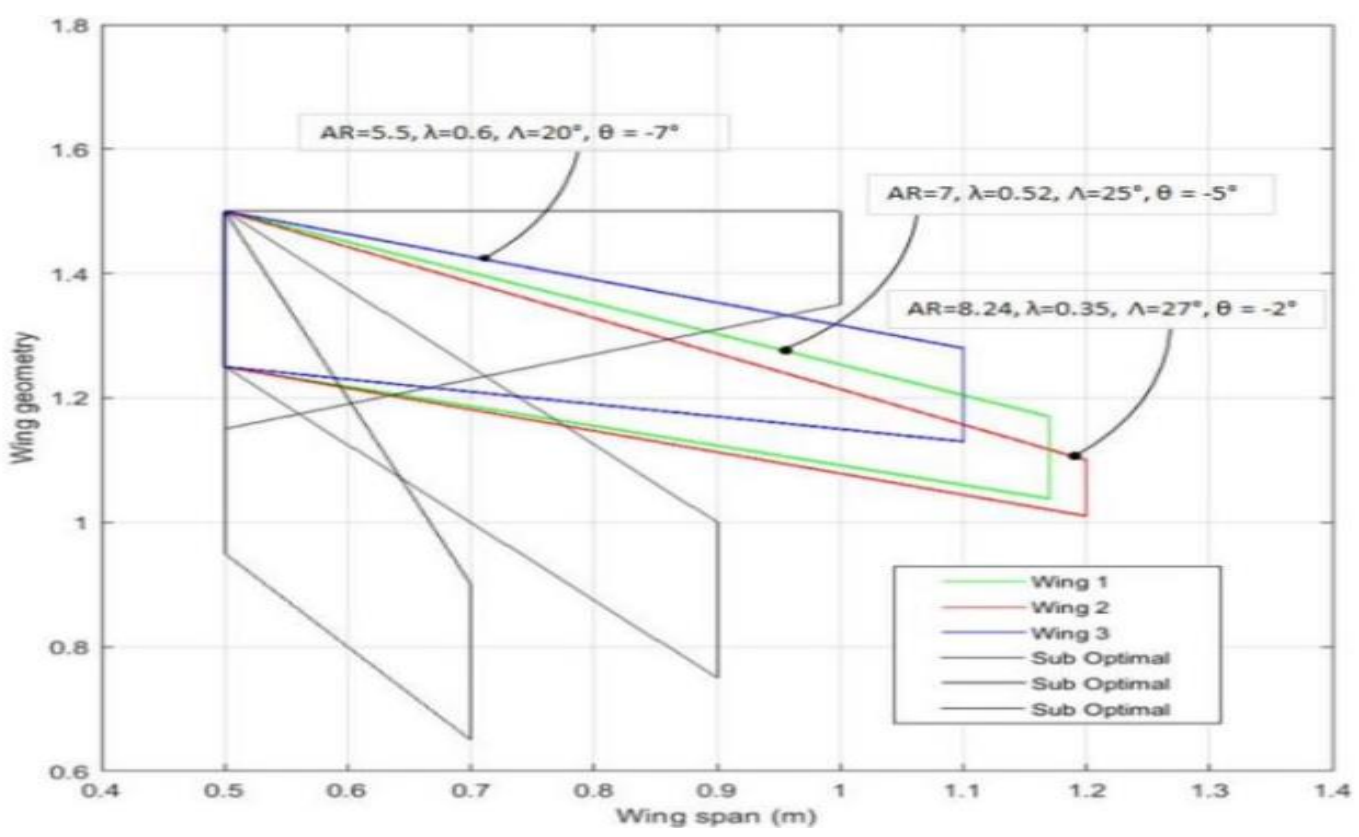

Figure 2 Wing geometry vs Wingspan

The curve at the left (Figure 3) corresponds to the three fittest individuals of the last generation along with some suboptimal solutions that were deemed unfit and cast out over time in the selection process.

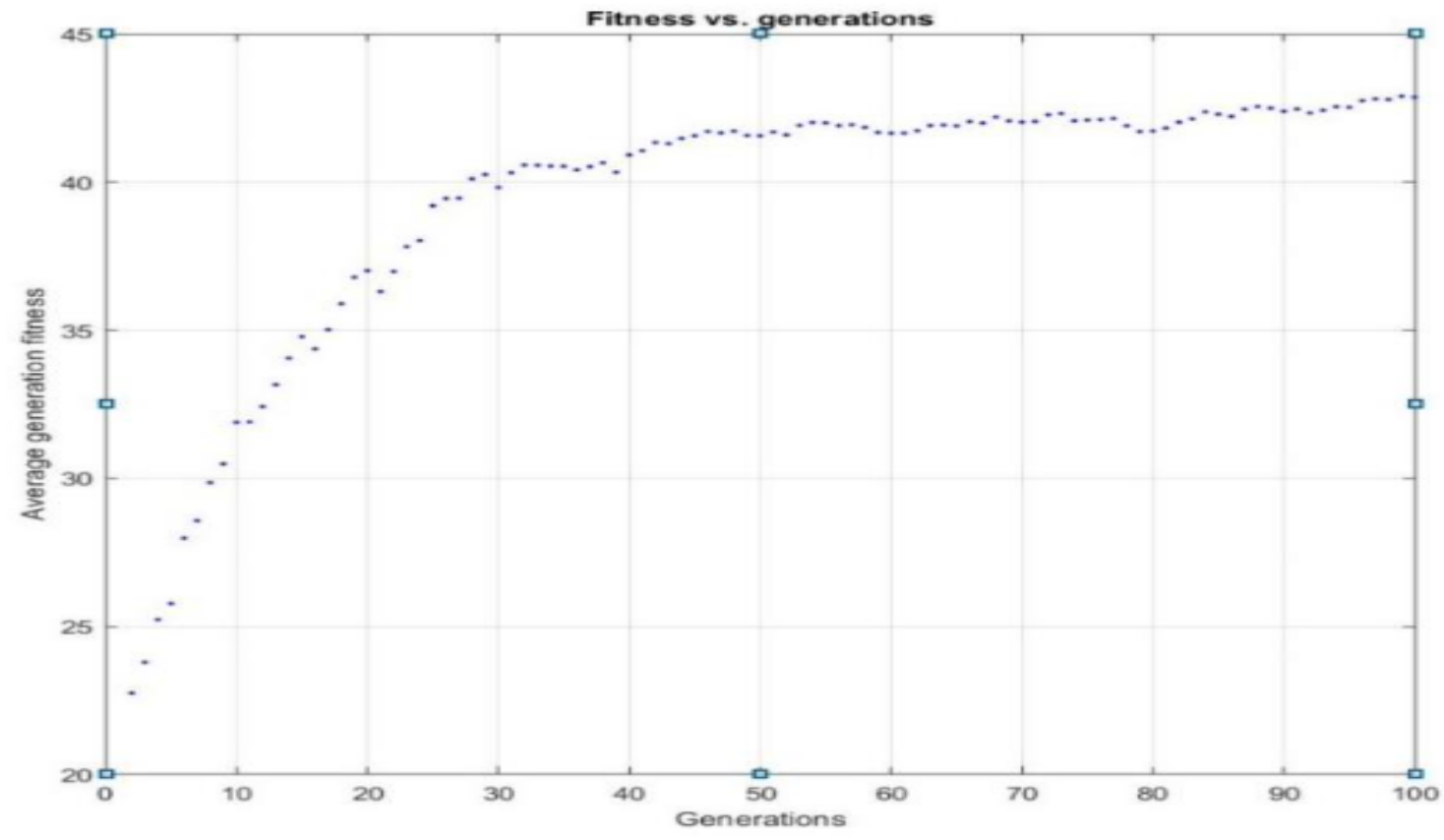

\section{Structural design}

Figure 3 Average generation Fitness vs Generation

Wings are an important subsystem of a UAV and along with structural robustness, equal consideration is also given to airworthiness. So, therefore, the process of the structural design of wings is carefully engineered to cater to the requirements of the mission. The proposed system has carbon fiber wings having a high strength to weight ratio thus allowing the selection of a higher load factor. The carbon fiber has high tensile strength, Extremely low thermal expansion, corrosion resistance, low density, and higher modulus of elasticity which ranges between 155-750 Gpa. If we use steel to get the same configuration it weighs more than carbon fiber by multiple of 5 times. Following the next step algorithm is modeled in MATLAB wherein the lift load, estimated using the distribution curve, is entered into the code to further calculate the optimum dimensions of the spars and local stress born by the wing.

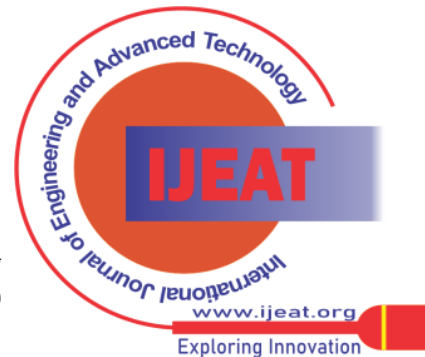




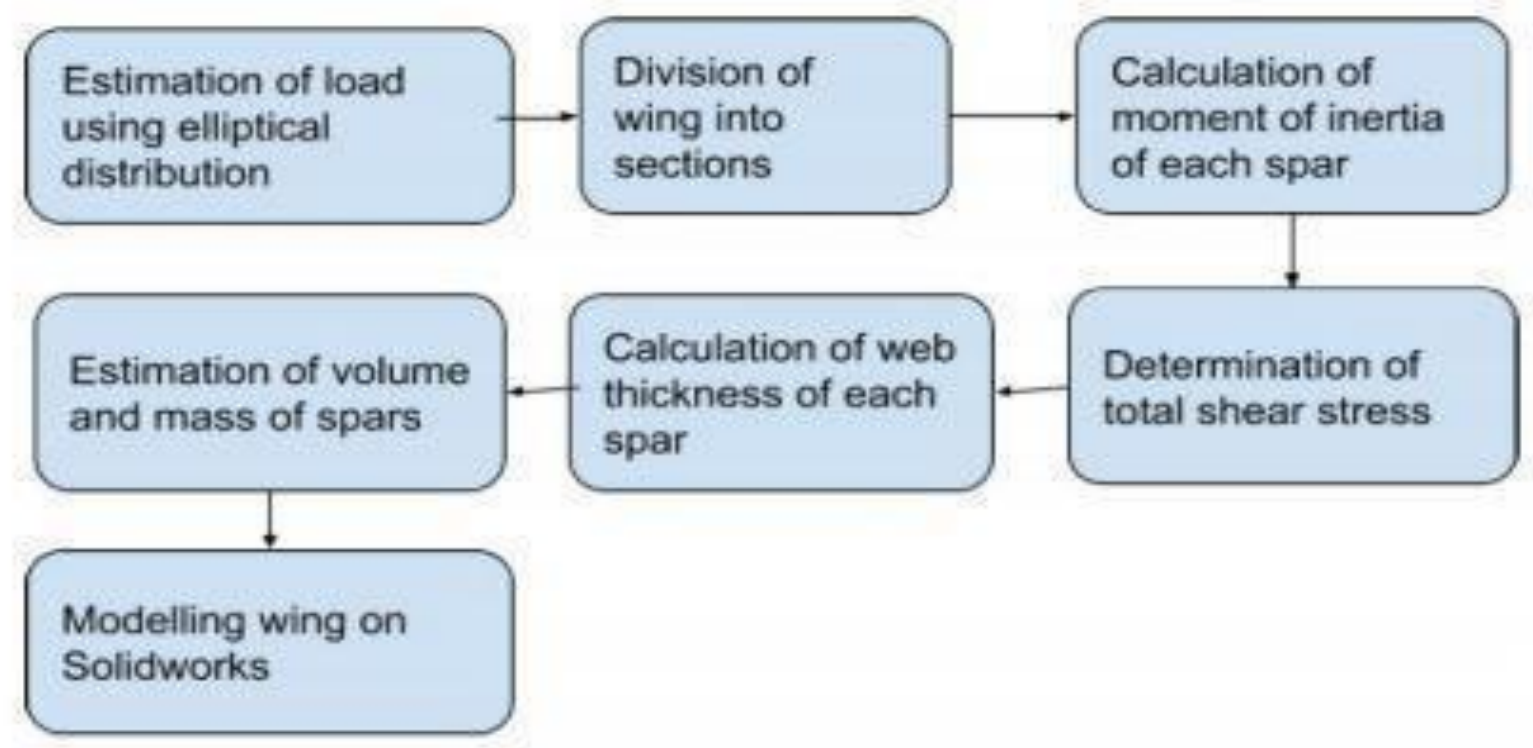

Figure 4 Algorithm for wing modeling

After dividing the wing into the number of divisions, the location of the center of pressure, position of spars is initially estimated. The Center of Pressure is 0.45 times the length of the chord while the Front spar position is 0.23 times the length of the chord and the Rear spar position is 0.66 times the length of the chord. All measurement is done from the leading edge wing and is modeled in Solidworks for post-processing.
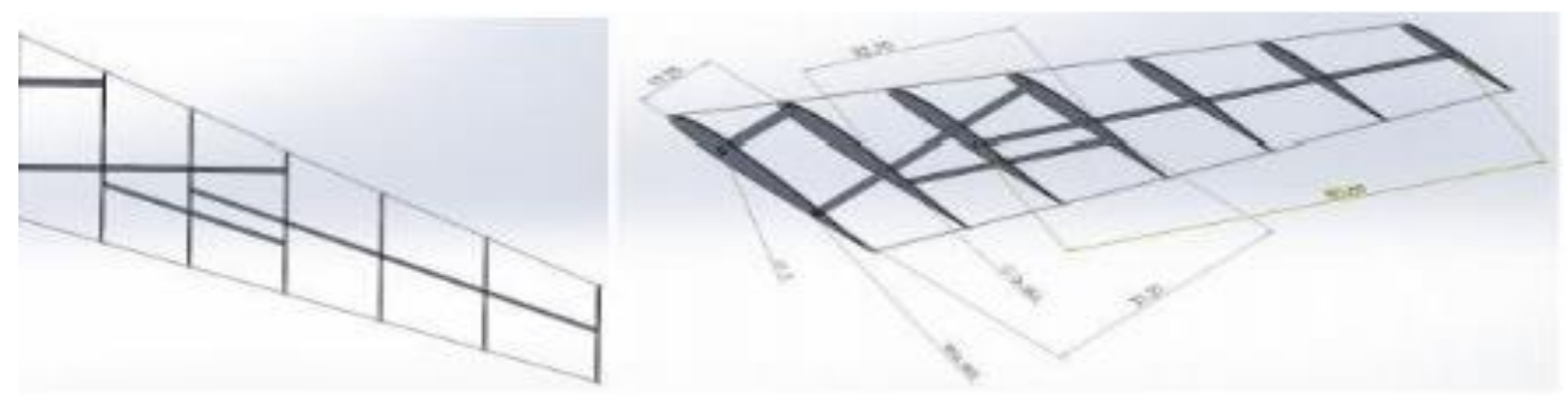

Figure 5 Wing Structural Design CAD

\subsection{Elevon Design}

Unconventional aircraft configurations such as Delta winged and Blended wing body aircraft cannot use the conventional three-axis

the flight control system, therefore they use a device called Elevons. Elevons are the control surfaces that combine the function of pitching and rolling [3]. The major challenge in designing elevons is to take into account the combined authority of longitudinal and lateral axes control. While designing the elevons, roll rate requirements are the primary criteria for an unconventional aircraft while pitch moment is majorly thrust controlled.

The process of elevon designing consists of finding the following four parameters.

1. Elevon chord/span (Ce/be)

2. Planform area of elevon (Se)
3. Elevon max deflection

4. Location of elevon inboard

\section{HANDLING QUALITY REQUIREMENTS}

\section{A. Aircraft class}

According to MIL-F-8785C [4], there are four major classes of aircraft classification: I, II, III, and IV. The handling qualities for each class differ, for example, Class IV is considered to have the highest control requirements than the other three classes. In Class, I aircraft with smaller weight, light utility, and lighter observations are included. By looking at the specifications, the hybrid VTOL-BWB UAV belongs to class I.

Published By:

Blue Eyes Intelligence Engineering and Sciences Publication (BEIESP)

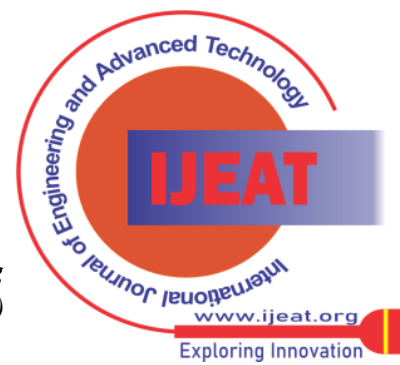


Table 2:Aircraft Classes

\begin{tabular}{|l|l|}
\multicolumn{1}{|c|}{ Table 2:Aircraft Classes } \\
\hline 1 & Aircraft Characteristics \\
\hline II & Small, light aircraft (MTOW $<5000 \mathrm{~kg}$ ) and low maneuverability \\
\hline III & Medium aircraft (MTOW b/w 5000 and $29000 \mathrm{~kg})$ \\
\hline IV & For heavy and large aircraft with medium maneuverability (MTOW $>29000 \mathrm{~kg})$ \\
& $\begin{array}{l}\text { Highly maneuverable aircraft such as missiles and fighter planes with no limit on } \\
\text { weight as such. }\end{array}$ \\
\hline
\end{tabular}

\section{B. Flight Phase}

Flight phase is another parameter that affects control and maneuverability and it varies for different missions. A tradeoff study shows that our UAV belongs to category B because it usually accomplishes maneuvering without any precision tracking but in some cases, accurate flight-path control is required and it also has the capacity of a low altitude parachute extraction system.

\section{Control surface configuration}

The concept behind designing the control surface is to make them work primarily as a moment generator. During a flying pitch, yaw and roll are required for controlling and the regular UAVs have an aileron, elevator, and rudder for generating moments. Any variation to the conventional configuration is responsible for a different combination or multiple axes controlled moment generators for example- a BWB UAV with vertical take-off and landing capabilities employs elevons for controlling. The final configuration is the culmination of a trade-off between the design and stability requirements.

\section{Matlab Code}

Once all constraints and parameter value is decided, the final sizing and positioning can be done using MATLAB [6] code. The parameters shown in Table 3 are the primary requirements for mathematical calculations involving elevon positioning.

Table 3: Matlab Parameters

\begin{tabular}{|l|l|l|}
\hline Parameters & Ixx & $0.37 \mathrm{~kg} / \mathrm{m} 2$ \\
\hline $\begin{array}{l}\text { Longitudinal axis inertial } \\
\text { moment }\end{array}$ & Ct & $0.17 \mathrm{~m}$ \\
\hline Tip chord & b & $1.72 \mathrm{~m}$ \\
\hline Span of wing & S & $0.36 \mathrm{~m} 2$ \\
\hline Area of Wing platform & TR & 0.65 \\
\hline Taper ratio & AR & 8 \\
\hline Aspect ratio & Cdr & 1 \\
\hline Rolling drag coefficient & mac & $0.2 \mathrm{~m}$ \\
\hline Mean aerodynamic chord & tau & 0.37 \\
\hline Elevons effectiveness parameter & Vs & $18 \mathrm{~m} / \mathrm{s}$ \\
\hline Stall speed & elevon_max_def & $(15 * \mathrm{pi}) / 180 \mathrm{rad}$ \\
\hline Elevon maximum deflection & & $0.3 \mathrm{~m}$ \\
\hline Wing root chord & Wcr & $2.2 \mathrm{~s}$ \\
\hline Time of roll & t & \\
\hline
\end{tabular}

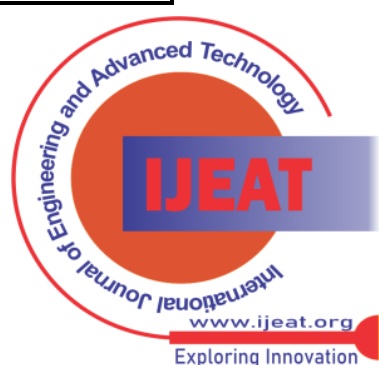


Wings having a lower aspect ratio has higher wingtip vortices resulting in higher induced drag coefficient and higher downwash and lower lift as compared to higher wing aspect ratio [1].

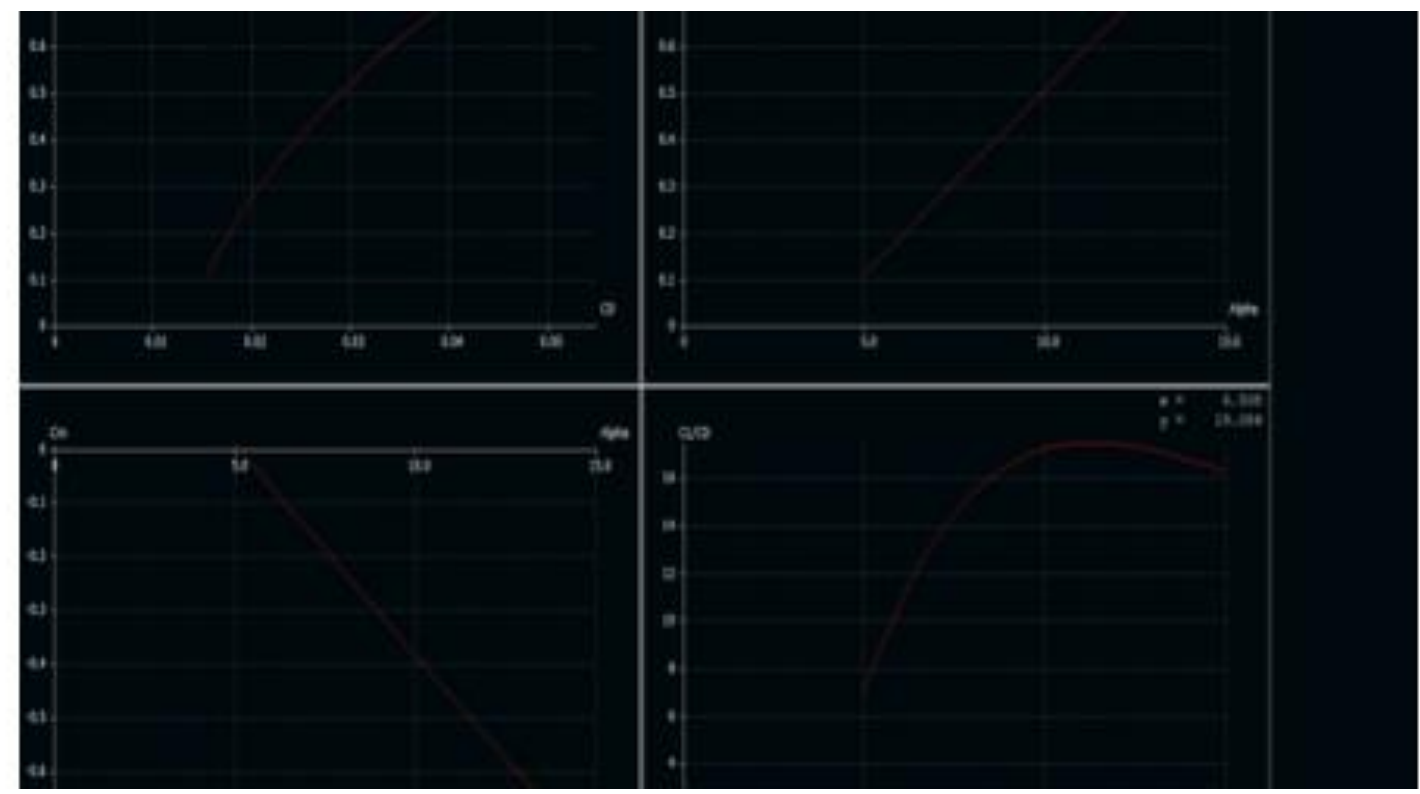

Figure 9 Plots of $\mathrm{cl}$ vs alpha, $\mathrm{cm}$ vs alpha, $\mathrm{cm}$ vs cl, cl/cd vs alpha for selected optimum design

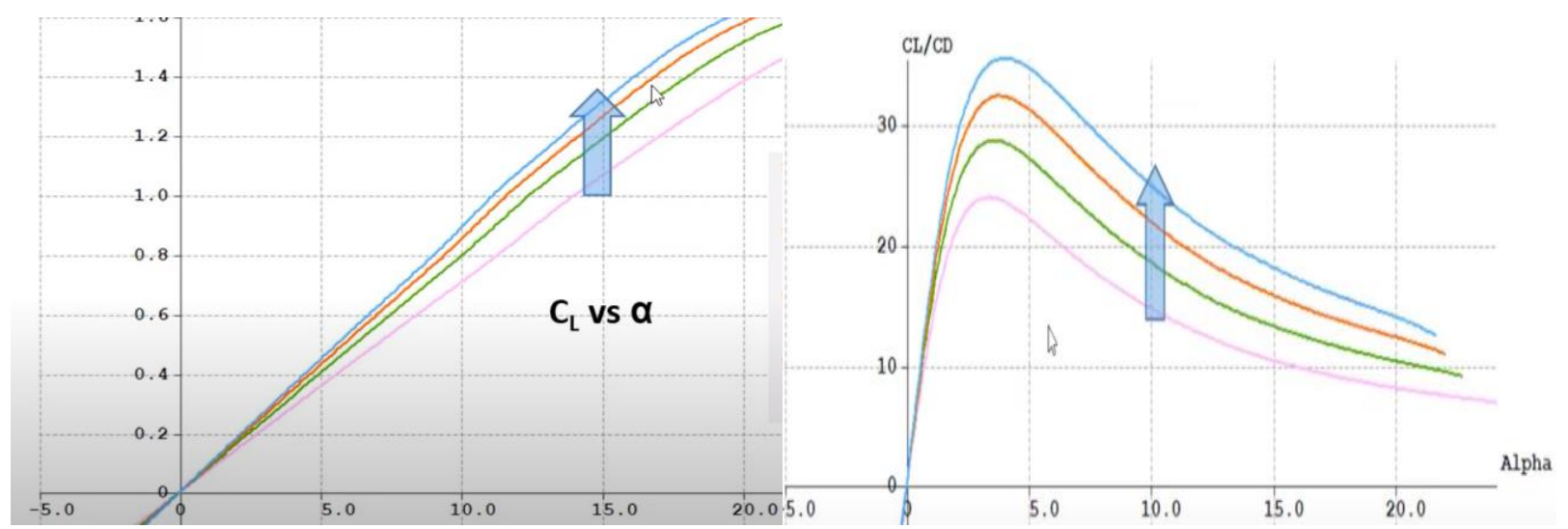

Figure 10*a Plots of cl vs alpha \& Figure 10*b cl/cd vs alpha [for aspect ratio of 6-9].

V. RESULTS

We can conclude from figure 9.* that increasing aspect ratio increases lift but the angle of attack at max cl decreases. In figure $9 . * b$ lift to drag ratio increases but we can see with increasing angle of attack it keeps on decreasing. So we have to choose an optimum angle of attack. Now weight due to higher aspect ratio significantly reduces lift so aspect ratio of 7 is the most optimal for design as validated on XFLR5. In the present design of BWB UAV, a suggestive design method genetic algorithm for wings has been taken from paper [7] and further optimized for aerodynamic fitness, geometric fitness, and structural fitness. After arriving at the initial draft Matlab code is written to design elevons and their positions. The value obtained for elevons is comparable with values obtained in paper [8] with a margin of error of $1.62 \%$. Results of variation of cl with aoa obtained from xflr5 and CFD simulations for aoa in range of 4-8 are in line with results in paper [9] where test velocity is $180 \mathrm{~m} / \mathrm{sec}$ wheres in the present study it is $264 \mathrm{~m} / \mathrm{sec}$ which later validates the research work done. The novelty of the present study is the selection of optimized initial geometry

and control surfaces and validation with numerical mathematical and simulation models.

\section{CFD ANALYSIS OF WING OF BWB UAV}

Analysis of BWB UAV is done in three phases, the first of which is pre-processing in which CAD geometry is selected then geometrical operation flow volume extraction is used and an enclosure of particular dimensions is formed to minimize effects of the wall on fluid flow interaction after which meshing is done. In Mesh selection we have selected the Hex Dominant algorithm after which refinement is done in the refinement surface and region refinement is chosen. In the region, refinement mode is inside and the maximum edge length is $0.5 \mathrm{~m}$. In surface refinement, min length chosen is $0.05 \mathrm{~m}$ and the $\max$ is $0.1 \mathrm{~m}$. In geometric primitive, a particular dimension of the cartesian box is chosen.

Published By:

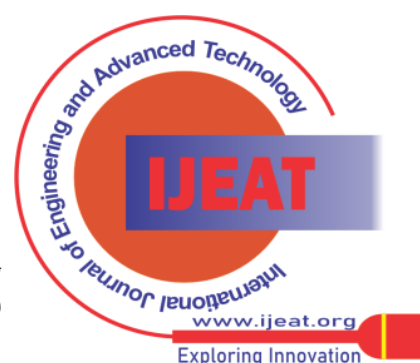




\section{Design of Elevons, Wings, and Performance Investigation for A Blended Wing Body UAV}

The second phase is of simulation in which incompressible airflow and viscosity model selected is Newtonian and is modeled with initial conditions of pressure, a velocity which is $264 \mathrm{~m} / \mathrm{s}$, turbulent kinetic energy with specific dissipation and boundary condition of velocity, pressure, and wall, smooth solver for velocity is selected and GAMG of pressure is selected. The third phase is post-processing in which we get results of force coefficients like lift, moment, drag, $\mathrm{cl}(\mathrm{f}), \mathrm{cl}(\mathrm{r})$ then we get convergence plot of inlets, outlets, domains, walls\& residuals and final was solution field of wall distance(y), Y plus, turbulent kinetic energy, pressure, velocity, wall shear stress \& vorticity.

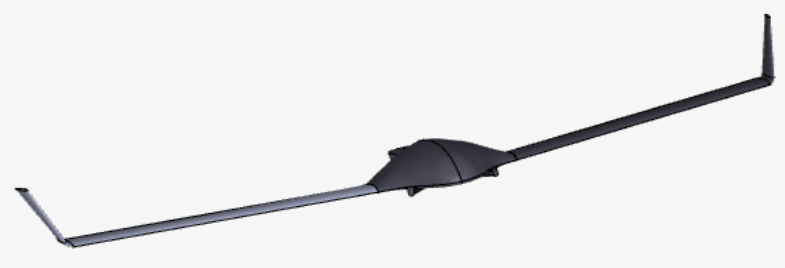

Figure 11 CAD design of UAV

Cad geometry of UAV is designed in AutoCAD software and then simulations are performed at later stages.

\section{SIMSCALE POST PROCESSING VIEWER}

Solid color on wings of UAV represents the pressure while streamline and side slicer represent velocity profile in figure 12.

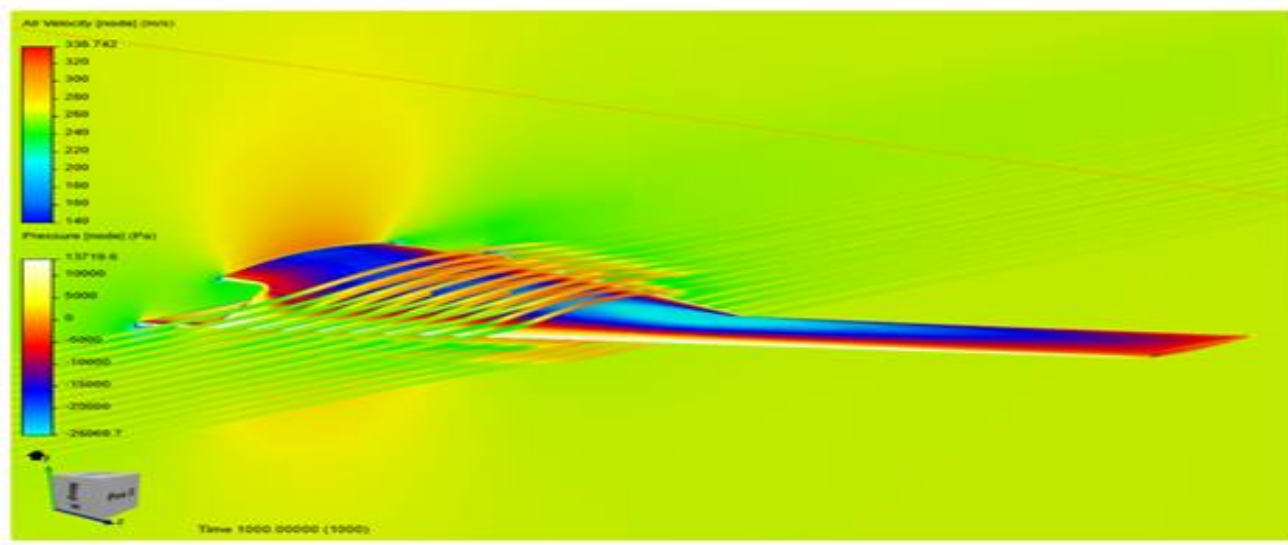

Figure 12 Solid color on wings represent pressure and slice represent velocity profile

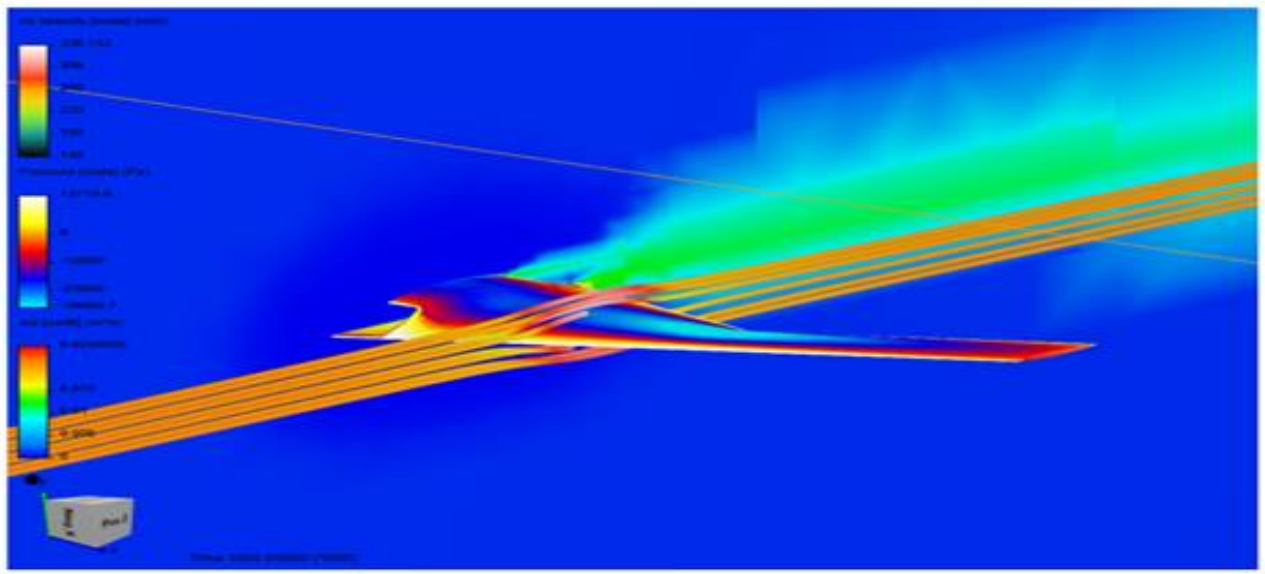

Figure 13 Solid color on wings represent pressure and slice represent viscosity

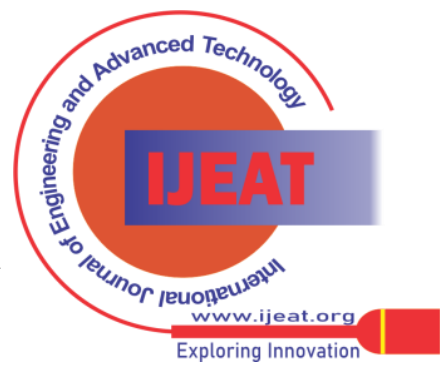




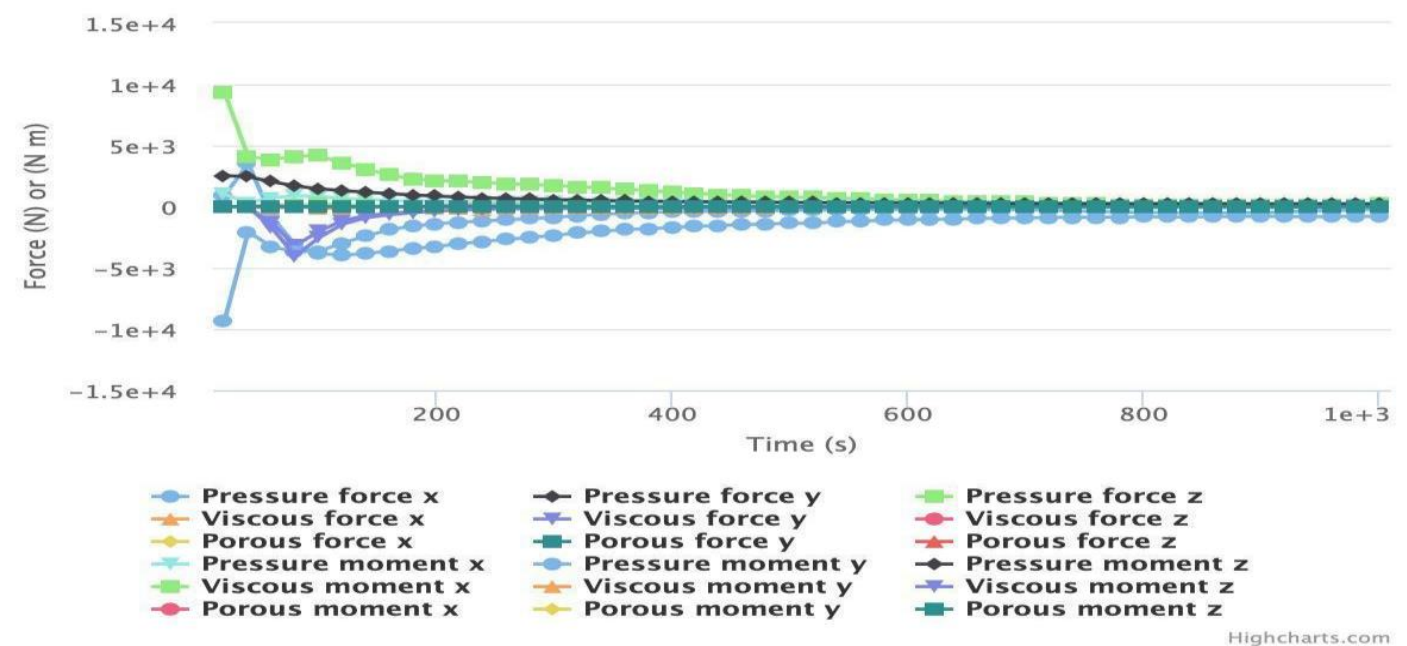

Figure 14 Showing Post-processing result of forces and moment

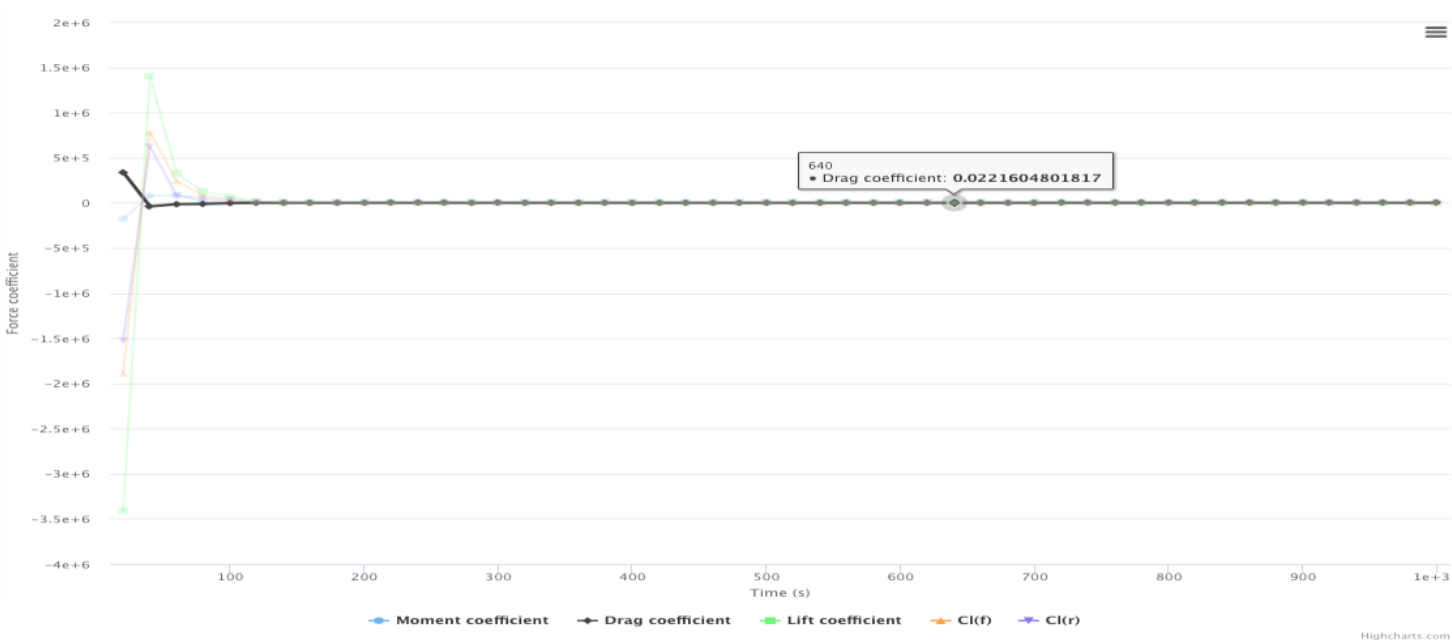

Figure 15 Showing Post-processing result of drag coefficient with value at 640 sec.

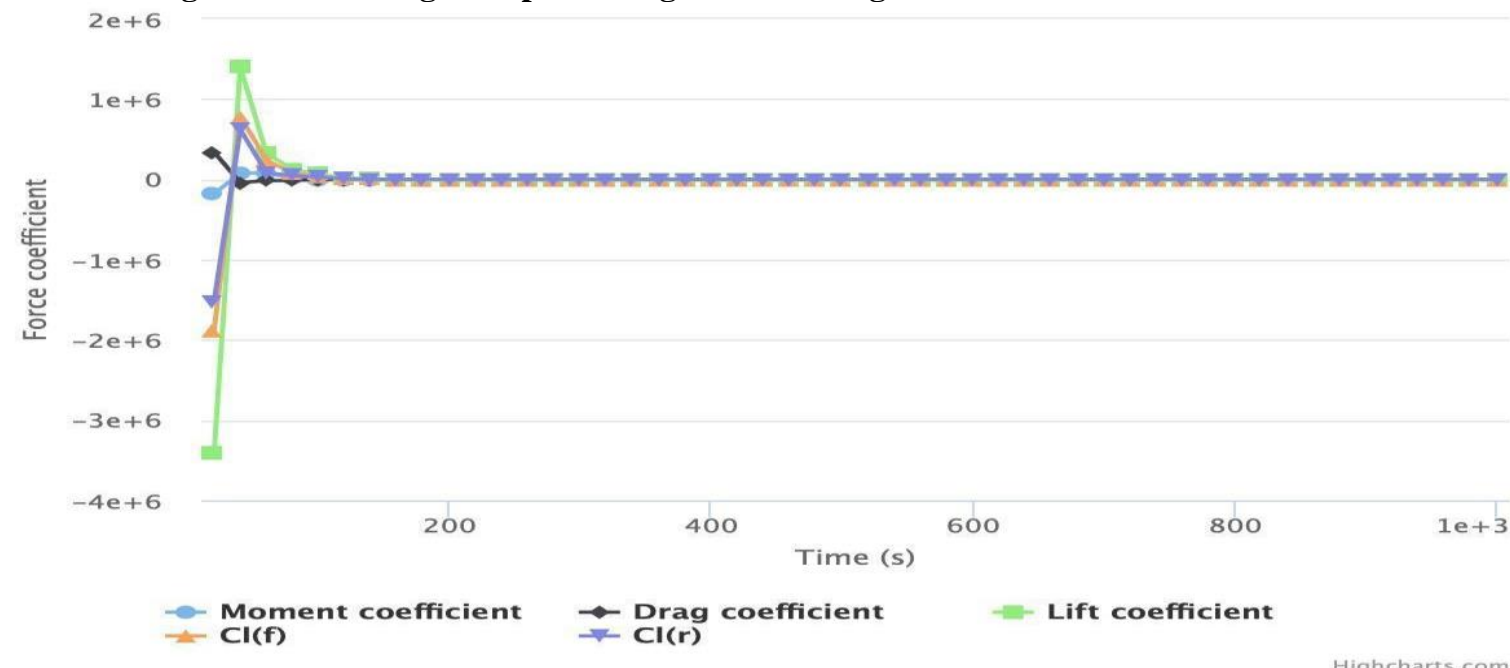

Figure 16 Showing Post-processing result of Force coefficient which includes a coefficient of moment, drag, lift, cl(f), cl(r) wrt to time

\section{CONCLUSIONS}

This work presented an optimum design of wings, elevons, variation curve of $\mathrm{cl}, \mathrm{cd}$, and alpha and calculates values of lift coefficient, the drag coefficient of BWB UAV obtained through CFD simulations and compares with a drag coefficient of known geometries obtained through experiments like streamlined body, bird, sphere, cylinder, aircraft wing which is greater than 0.04 mostly. The drag coefficient of the designed BWB UAV comes out to be

Retrieval Number: 100.1/ijeat.A31521011121

DOI: 10.35940/ijeat.A3152.1011121

Journal Website: www.ijeat.org precisely around 0.02216 . The value obtained from simulation is less than known geometries and the aerodynamic design of BWB UAV is perfect. In the force and moment plot, the main forces and moment are in $\mathrm{x}$ direction acting on the fuselage.

Published By:

Blue Eyes Intelligence Engineering and Sciences Publication (BEIESP)

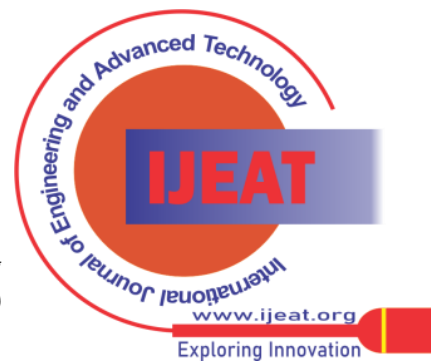




\section{Design of Elevons, Wings, and Performance Investigation for A Blended Wing Body UAV}

The pressure, velocity, wall shear, turbulent kinematic viscosity profile is also plotted. A new design method based on the lift equation for sizing control surfaces of an unstable hybrid VTOL- BWB UAV is presented. The author has written code on MATLAB for optimum sizing and positioning of elevons and plotted aerodynamic characteristics on XFLR5 and later done pre-processing, simulation, and post-processing results on Simscale with Computational fluid dynamics methodology. The Author's thesis topic is based on the design of wings, elevons, and winglets and numerical investigation on their performance. The author has done extensive literature research over the aerodynamics of wings, materials, and simulations to present effective design of control surfaces, and results obtained in the present study have been compared to validate the authenticity of the research work. The presented result will be helpful to future researchers and airframe engineers in selecting an optimum design of UAVs. The author believes that there are still certain limitations of this research due to the research facility available but it will help further research in BWB UAV technology. The author in the future is planning to test experimental results with simulation results of the proposed method to calculate the amount of error in results which will open scope for further improvement.

\section{NOMENCLATURE}

\begin{tabular}{|l|l|l|}
\hline S & Wing area & {$\left[\mathrm{m}^{2}\right]$} \\
\hline AR & Aspect ratio & -- \\
\hline CL $_{C}$ & Lift coefficient of the wing at cruise & -- \\
\hline$\rho$ & Density of air & {$\left[\mathrm{kg} / \mathrm{m}^{3}\right]$} \\
\hline We & Empty Weight & $\mathrm{kg}$ \\
\hline CM & Wing pitching moment & -- \\
\hline Vs & Stall speed & $\mathrm{m} / \mathrm{s}$ \\
\hline F & Load & $\mathrm{N}$ \\
\hline TR & Taper ratio & \\
\hline $\begin{array}{l}\text { GTO } \\
\text { W }\end{array}$ & Gross takeoff weight & $\mathrm{kg}$ \\
\hline MAC & Mean aerodynamic chord & \\
\hline
\end{tabular}

\section{REFERENCES}

1. Raymer, D Daniel.P., "Aircraft Design: A Conceptual Approach”, American Institute of Aeronautics and Astronautics, Washington D.C,

https://soaneemrana.org/onewebmedia/AIRCRAFT\%20DESIGN\%2 0;\%20A\%20Conceptual\%20Approach\%20BY\%20DANIEL\%20P\% 20RAYMER.pdf

2. John D David. Anderson, "Fundamentals of Aerodynamics", Boston: McGraw- Hill, 2001, Pages-892

3. Sadraey, M., Colgan, R., "A Systems Engineering Approach to the Design of Unconventional Control Surfaces for UAVs," AIAA2008-1124, 46th AIAA Aerospace Sciences Meeting and Exhibit, Reno, Nevada, 7-10, 2008, doi: 10.2514/6.2008- 1124

4. Sadraey, H. M Mohammad, "Aircraft Design: A system engineering Approach”, Daniel Webster College, New Hampshire, USA, 2013.

5. Sadraey, M., Colgan, R., "A Systems Engineering Approach to the Design of Control Surfaces for UAVs," AIAA-2007-660, 45th AIAA Aerospace Sciences Meeting and Exhibit, Reno, Nevada, Jan. 8-11, 2007, doi: 10.2514/6.2007-660

6. "MATLAB Software, Version R2018b," The Mathworks, 1994 2018.

https://www.mathworks.com/search.html?c\%5B\%5D=entire_site\&q =MATLAB\%20Software\%2C\%20Version\%20R2018b\&page=1

7. Rastogi, V., Raj Chauhan, H., "design, analysis, fabrication, and testing of an unmanned aerial vehicle wing- A system engineering

Ashutosh Kumar, Research scholar at Delhi Technological University (Formerly Delhi College of Engineering), with background in Thermal mechanical system design, development, analysis, experimentation and testing. Strong technical proficiency with system \& component engineering, system/vehicle architecture, modeling \& simulation, packaging, wiring harness design, system optimization. In-depth knowledge of Scilab xcos, Matlab, Fluent, Ubuntu, ROS. Having interest in designing launch vehicles and other components in rockets and aerospace systems and made significant contributions with project work and conference papers. He is Currently Completing master's thesis in area of BWB UAV.

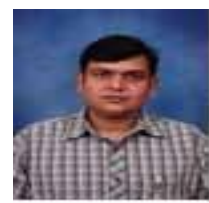

Raghvendra Gautam, is Presently working as an Assistant Professor of Mechanical Engineering at Delhi Technological University (Formerly Delhi College of Engineering). He has published more than 20 research papers $\left(5^{+} \mathrm{SCI}, 5^{+}\right.$Scopus $)$in the International Journals of repute and in Indian Journals and Conferences. He brings with him a combination of being a distinguished academician, an exemplary researcher, visionary educational administrator, a professional consultant with a positive attitude, and a profoundly professional approach for intimate industry interaction. In addition to teaching at PG and UG levels has made a significant contribution to $R \& D$ in the area of alternative fuels for use in a variety of off-road engines and vehicles. Ph.D. scholars have already been awarded degrees under his supervision whereas many are in a different stage of their research pursuit. M.Tech. Students have also completed their projects/degrees under his guidance. He also heads the NCC unit of Delhi Technological University. 